\title{
Developing a Genetic Fuzzy System Model for Cost-Benefit Analysis
}

Saurabh Singh ${ }^{1}$, Praveen Kumar Shukla ${ }^{2}$, Rashmi Ranjan ${ }^{3}$, Anurag Kumar ${ }^{4}$

${ }^{1}$ Department of Computer Science \& Engineering, Babu Banarasi Das University, Lucknow, India

E-mail: sau91.singh@gmail.com

${ }^{2}$ Department of Information Technology, Babu Banarasi Das Northern India Institute of Technology Lucknow, India

E-mail: praveenshuklaniec@yahoo.co.in

${ }^{3}$ Department of Computer Science \& Engineering, Babu Banarasi Das University, Lucknow, India

E-mail: rashmibbd2011@gmail.com

${ }^{4}$ Department of Computer Science \& Engineering, Babu Banarasi Das University, Lucknow, India

E-mail:anurag.ms0362@gmail.com

\section{ABSTRACT}

Cost benefit analysis is a systematic approach for calculation and analyzing the cost of a project. Soft computing approaches are also applicable to deal with cost benefit analysis. In this paper Mamdani fuzzy system has been developed for cost benefit analysis. The genetic optimization of the model is carried out. The interpretability and accuracy features are also analyzed.

\section{Indexing terms/Keywords}

Cost Benefit Analysis(CBA), Genetic fuzzy system(GFS), Fuzzy Rule Based System(FRBS), Interpretability Accuracy trade off, GUAJE.

\section{Council for Innovative Research}

Peer Review Research Publishing System

Journal: INTERNATION JOURNAL OF COMPUTERS AND TECHNOLOGY

Vol. 13 , No. 4

editorijctonline@gmail.com

www.cirworld.org/journals 


\section{INTRODUCTION}

Cost and completion time are the two important features of the project. Several approaches have been developed to approximate cost of the project. Cost benefit analysis is an analytical model to deal with cost approximation of the project [6]. Normally cost benefit analysis [1] have four parameters that is cost on sale (COS), quantity of sale (QOS), cost at variation (CAV), cost at fixed (CAF). To reduce the associated risk with the model different probabilistic and stochastic models have been developed.

In this paper a genetic fuzzy system has been proposed and implemented using open access software GUAJE. Fuzzy systems are applied to deal with uncertainty and imprecision existing in the applications [6, 7, 8]. Interpretability and Accuracy are the important features of the fuzzy systems $[7,8]$. They are contradicting with each other .i.e. one can be improved at the cost of other. This situation leads to interpretability-Accuracy trade off [9, 10]. Fuzzy concepts are also used to data base applications [11, 12]. Fuzzy logic is applied in rule base systems leading to a new area called fuzzy rule based systems (FRBS).

Genetic algorithm has been used to optimize the fuzzy system proposed for Cost benefit analysis [2]. This paper consists of 4 sections. Section 1 is related to the introduction. Section 2 is the description of proposed model. Experiments and result analysis are carried out in section 3. Section 4 is the conclusion and future scope.

\section{PROPOSED MODEL}

Fuzzy if-then rules are essential functioning component of any FRBS. Fuzzification, Knowledgebase, Defuzzification and Inference engine are different components of FRBS. Fuzzyfication interface converts crisp information into fuzzy. Inference engine processes the fuzzy input information into fuzzy output information. KB is the repository of knowledge stored in the form of fuzzy if-then rules. Basically KB has two components; Data base (DB) and Rule base (RB). DB is the repository of membership functions and scaling functions. Whereas RB is the fuzzy if - then rules. Several kinds of FRBS are introduced in the literature. These are as follows:

1. Linguistic or Mamdani FRBS

2. Takagi - Sugeno (TS) fuzzy systems

3. Approximate or scatter partition FRBS [3]

\section{Linguistic or Mamdani FRBS}

In this FRBS the if -then rules have linguistic values in the consequent part of the rule, the rules are as follows:

$R_{i}$ : if $X_{i 1}$ is $A_{i 1}$ and. ...and $X_{\text {in }}$ is $A_{\text {in }}$ then $Y$ is $B_{i}$

\section{TS type FRBS}

The rule structure in this FRBS have a polynomial function in the consequent part of the rule, the rules are as follows:

$R_{i}$ : if $X_{i 1}$ is $A_{i 1}$ and.............and $X_{i n}$ is $A_{i n}$ then $Y=P\left(X_{i 1}\right.$

..., $\left.X_{\text {in }}\right)$, Here $P(\ldots .$.$) be a polynomial function.$

\section{Approximate or Scatter partition FRBS}

In this variable the fuzzy variables are directly used in the rules. The fuzzy if -then rules are as follows:

$R_{i}$ : if $X_{i 1}$ is $A^{\wedge}{ }_{i 1}$ and.... and $X_{i n}$ is $A^{\wedge}{ }_{\text {in }}$ then $Y$ is $G^{\wedge}{ }_{i 1}$

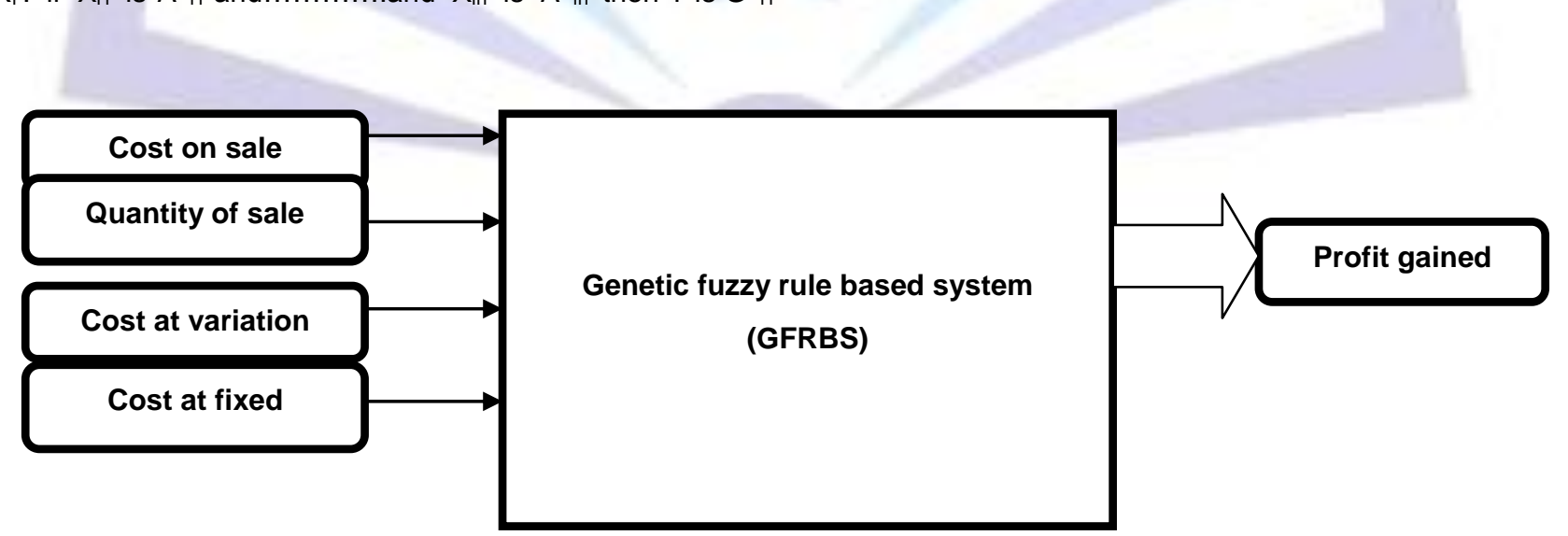

Fig 1-Controlling of total profit of CBA (cost benefit analysis) using GFRBS 
A fuzzy system has been proposed for estimating profit in cost benefit analysis procedure. The input parameter are Cost on sale, Quantity of sale, Cost at variation, Cost at fixed. The value for these input and output parameters are tabulated below in Table 1 and Table 2 gradually.

Table- 1 (Membership functions of input variables)

\begin{tabular}{|l|l|l|}
\hline Input Variable & Level & Range \\
\hline Cost on sale (COS) & Poor & $1800-2050$ INR \\
\cline { 2 - 3 } & Average & $1950-2200$ INR \\
\cline { 2 - 3 } & High & $2150-2400$ INR \\
\hline Quantity of sale (QOS) & Poor & $8000 \mathrm{~K}-9000 \mathrm{~K}$ INR \\
\cline { 2 - 3 } & Average & $8500 \mathrm{~K}-9500 \mathrm{~K}$ INR \\
\cline { 2 - 3 } & High & $900 \mathrm{~K}-1000 \mathrm{~K}$ INR \\
\hline Cost at variation (CAV) & Poor & $1150-1350$ INR \\
\cline { 2 - 3 } & Average & $1450-1650$ INR \\
\cline { 2 - 3 } & High & $1000 \mathrm{~K}-1150 \mathrm{~K}$ INR \\
\hline \multirow{5}{*}{ Cost at fixed (CAF) } & Poor & $1100 \mathrm{~K}-1250 \mathrm{~K}$ INR \\
\cline { 2 - 3 } & Average & \\
\cline { 2 - 3 } & High & \\
\hline \multirow{5}{*}{} & & \\
\hline
\end{tabular}

Table- 2 (Membership functions of output variable)

\begin{tabular}{|l|l|l|}
\hline Output variable & Level & Range \\
\hline Profit gained (PG) & Very poor & $0-40,000$ INR \\
\cline { 2 - 3 } & Poor & $40,000-8,00,000$ INR \\
\cline { 2 - 3 } & Average & $8,00,000-20,00,000$ INR \\
\cline { 2 - 3 } & High & $20,00,000-40,00,000$ INR \\
\cline { 2 - 3 } & Very high & $40,00,000-1,00,00,000$ INR \\
\hline
\end{tabular}

\section{EXPERIMENTS AND RESULT ANALYSIS}

The proposed model has been implemented using tool GUAJE [4]. GUAJE stands for Generating Understandable and Accurate fuzzy models in a Java Environment. It implements the fuzzy modelling methodology named as Highly Interpretable Linguistic Knowledge (HILK) [5], which is aimed at yielding a good interpretability-accuracy trade-off thanks to combining expert and induced knowledge in a common framework. It consists on a computational environment for building interpretable and accurate fuzzy systems by means of combining several pre-existing open source tools, taking profit from the main advantages of each individual tool by analogy with the main idea underlying to Soft Computing. The data set for the proposed model is detailed in table 3. 
Table- 3 (Used data set)

\begin{tabular}{|l|l|l|l|l|l|l|}
\hline Rule & Type & $\begin{array}{c}\text { If Variable } \\
1\end{array}$ & $\begin{array}{c}\text { AND } \\
\text { Variable 2 }\end{array}$ & $\begin{array}{c}\text { AND } \\
\text { Variable 3 }\end{array}$ & $\begin{array}{c}\text { AND } \\
\text { Variable 4 }\end{array}$ & $\begin{array}{c}\text { THEN } \\
\text { Variable 5 }\end{array}$ \\
\hline 1 & 1 & 2150.0 & 1150.0 & 900000.0 & 900000.0 & 4000000.0 \\
\hline 2 & 1 & 2150.0 & 1250.0 & 900000.0 & 950000.0 & 4100000.0 \\
\hline 3 & 1 & 2200.0 & 1200.0 & 800000.0 & 975000.0 & 4200000.0 \\
\hline 4 & 1 & 2250.0 & 1250.0 & 700000.0 & 800000.0 & 4300000.0 \\
\hline 5 & 1 & 2250.0 & 1300.0 & 600000.0 & 750000.0 & 4350000.0 \\
\hline 6 & 1 & 1800.0 & 1450.0 & 700000.0 & 850000.0 & 4000000.0 \\
\hline 7 & 1 & 1850.0 & 1500.0 & 800000.0 & 950000.0 & 4500000.0 \\
\hline 8 & 1 & 1900.0 & 1550.0 & 900000.0 & 800000.0 & 4500000.0 \\
\hline 9 & 1 & 1950.0 & 1600.0 & 600000.0 & 700000.0 & 5000000.0 \\
\hline 10 & 1 & 2000.0 & 1575.0 & 750000.0 & 750000.0 & 6000000.0 \\
\hline
\end{tabular}

During the implementation the observed results for interpretability and accuracy are as follows:

Table- 4 (Interpretability measurement of corresponding data set in table- 3

\begin{tabular}{|l|l|}
\hline Nauck's Index & 0.034 \\
\hline Number of Rules & 10 \\
\hline Total Rule length & 40 \\
\hline Average Rule length & 4 \\
\hline Accumulated Rule Complexity & 10 \\
\hline Accumulated Rule Complexity(SC2011) & 118.393 \\
\hline Interpretability Index & 0.115 \\
\hline
\end{tabular}

Here the author found the result in term of accuracy $98 \%$ and interpretability index $(0.115)$.

The Genetic optimization on rule selection has been carried out with following parameters:

Number of generations $=5000$

Population length $=50$

Tournament size $=2$

Mutation probability $=0.1$

Crossover probability $=0.8$

Number of rules are the interpretability index,$w_{1}=0.5$ and $w_{2}=0.5$

Number of genes $=10$

Error index of initial $\mathrm{KB}=0.5$

\section{CONCLUSION \& FUTURE SCOPE}

A genetic fuzzy system has been implemented for the purpose of cost benefit analysis. The results of the proposed model are found satisfactory. In future the author would be interested to use interval type-2 fuzzy system for developing the proposed system. 


\section{ACKNOWLEDGMENTS}

I express thanks and gratitude to Mr. Praveen Kumar Shukla, Department of Information Technology, Babu Banarasi Das Northern India Institute of Technology for his encouraging support and valuable guidance in carrying out the project.

I also thanks to Miss Rashmi Ranjan, Computer Science Department, School Of Engineering, BBD University for making time for me from her tight schedules in reviewing the template and for her Ideas.

\section{REFERENCES}

[1] R. Layard and S. Glaisten, (1994), Cost Benefit Analysis, Cambridge University Press.

[2] D.E. Goldberg, (1989), Genetic Algorithm in search, optimization and machine learning, Addison-Wesley reading,

[3] Gomez-Skarmeta. A.F. and Jimenez. F. (1999), Fuzzy modeling with hybrid systems. Fuzzy sets and systems, Vol. 104, Issue 2, pp. 199-208, (1999).

[4] Alonso. J.M. and Magdalena. L. (2011). Generating Understandable and Accurate fuzzy models in a Java Environment, $9^{\text {th }}$ International Workshop on Fuzzy Logic and applications, Trani, Italy, 29-31 August, 2011, pp. 212219.

[5] Alonso. J.M., Magdalena. L., Guillaume. S., HILK: A new methodology for designing highly interpretable linguistic knowledge bases using fuzzy logic formalism. International Journal of Intelligent system, Vol 23, 761-794, (2008).

[6] P K Shukla, S P Tripathi, A New Approach for Tuning Fuzzy Knowledge Bases Using Interval Type-2 Fuzzy Sets \& Genetic Algorithms, Journal of Uncertainty Analysis \& Applications, vol. 2, (2014), doi:10.1186/2195-5468-2-4.

[7] P K Shukla, S P Triapthi, Interpretability Issues in Evolutionary Multi Objective Fuzzy Knowledge Base Systems, $7^{\text {th }}$ International Conference on Bio-Inspired Computing: Theories and Applications (BIC-TA 2012), ABV-IIITM, Gwalior, India, 14-16 December, (2012).

[8] P K Shukla, S P Tripathi, On the Design of Interpretable Evolutionary Fuzzy Systems (I-EFS) with Improved Accuracy, International Conference on Computing Sciences, LP University, India, Sept. (2012).

[9] P K Shukla, S P Tripathi, A Review on Interpretability accuracy trade off in Evolutionary Multiobjective Optimization Fuzzy system (EMOFS), Information, Switzerland, Vol. 3, No. 3, pp. 256-277, (2012).

[10] P K Shukla, S P Tripathi, A Survey on Interpretability-Accuracy Trade-Off in Evolutionary Fuzzy Systems, IEEE International Conference on Genetic and Evolutionary Computation (ICGEC 2011), Japan, 29 August-01 September, (2011).

[11] P K Shukla, M. Darbari, V K Singh, S P Tripathi, A Survey on Fuzzy Techniques in Object Oriented Databases, International Journal of Scientific \& Engineering Research, France, Vol. 2, No. 11, Nov. (2011).

[12] L.Sahoo, P K Shukla, Fuzzy techniques in object based modeling, International journal of information sciences and computing, vol. 2, No. 1, (2011).

[13] Poonam , S.P.Tripathi, P K Shukla, Uncertainty handling using Fuzzy logic in rule based system, International journal of advanced science and technology , vol. 45, pp. 31-46, (2012).

[14] O. Cordon, F. Herrera, F. Hoffmann, L. Magdalena, Genetic fuzzy systems: evolutionary tuning and learning of fuzzy Knowledge bases. World Scientific, July (2001).

[15] J. Cassilas, O. Cordon, F. Herrera, Interpretability improvements in linguistic fuzzy modeling, Heidelberg, Germany, (2003).

[16] J. M. Alonso, L. Magdalena, Special issue on Interpretable fuzzy systems, information science, Vol. 181, pp. 4331 4339, (2011). 


\section{Author' biography with Photo}

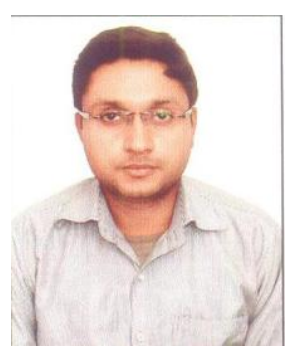

Saurabh Singh M.Tech Scholar Department of Computer Science \& Engineering, Babu Banarasi Das University, Lucknow, India . He received B.Tech Degree from SIT, Mathura (UPTU).

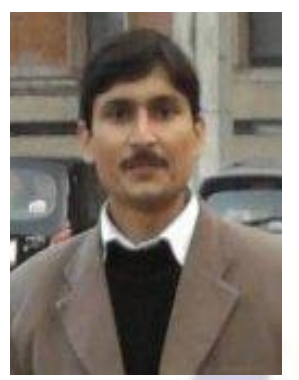

Praveen Kumar Shukla, Assistant Professor , Information Technology, BBD Northern India Institute Technology Lucknow. 